Revista Mídia e Cotidiano

Artigo Seção Temática

Volume 12, Número 2, agosto de 2018

Submetido em: 29/01/2018

Aprovado em: 29/05/2018

\title{
MAIS LIVRE PARA PUBLICAR: EFEMERIDADE DA IMAGEM NOS MODOS "GALERIA" E "STORIES" DO INSTAGRAM
}

\section{FREE TO PUBLISH: EPHEMERAL IMAGES IN “GALLERY” AND "STORIES” MODES OF INSTAGRAM}

\author{
André LEMOS $^{1}$; Catarina DE SENA ${ }^{2}$
}

\section{Resumo:}

Este artigo investiga o processo de produção de imagens para a rede social Instagram, considerando e comparando os modos de compartilhamento nas áreas denominadas "galeria" e "Stories". Interessa-nos entender as principais diferenças nos conteúdos produzidos e nos métodos utilizados pelos usuários. $\mathrm{O}$ argumento principal é que, com as novas redes sociais especializadas, a prática da fotografia é marcada pela efemeridade da imagem (fluxo em feeds e áreas de armazenamento temporário). Mais ainda, essas fotografias não primam pela qualidade técnica da imagem, sendo mais importantes enquanto vetor de socialização. Para dar suporte a essa pesquisa, foi realizada uma enquete com 173 usuários.

Palavras-chave: Instagram; Fotografia; Efêmero; Entretenimento.

\begin{abstract}
:
This paper aims to investigate the image processing on the Instagram, considering and comparing the sharing modes in two areas: "gallery" and "Stories". We are interested in understanding the main differences in the content produced and methods used by users. The main argument is that, with the new specialized social networks, the practice of photography is marked by the ephemerality of the image (flow in feeds and temporary storage areas). Moreover, these photographs do not excel in the technical quality of the image, being more important as a vector of socialization. To support this research, a poll was conducted with 173 users.
\end{abstract}

Keywords: Instagram; Photography; Ephemeral; Entertainment.

$1 \quad$ André Lemos é professor titular da Faculdade de Comunicação da UFBA. Pesquisador do CNPq (almlemos@gmail.com).

$2 \quad$ Catarina de Sena é jornalista (catarinaficouseria@gmail.com). 
Introdução

O presente estudo busca compreender o novo regime social da prática fotográfica com as redes sociais, particularmente com as novas ferramentas de publicação temporária das fotos. Nos interessa pensar a circulação instantânea de imagens na internet com recorte para a lógica do crescente movimento de volatilidade, atentando para um fenômeno recente que, além de instantâneo, deixa rastros temporários na rede. Para isso, analisamos o Instagram, rede social mais importante para compartilhamento de fotografia, comparando o uso da galeria (área de publicação padrão) e do Stories (área de publicações que se apagam em 24h). Para tanto, foi realizada, em 2017, uma pesquisa com 173 usuários a partir de um questionário na internet e complementada por entrevistas focadas com 3 usuárias ${ }^{3}$.

Se a fotografia já estava em um regime de efemeridade, visto o fluxo dessas imagens em timelines nas redes sociais, hoje essa característica é ainda mais forte com os sistemas de exposição temporária de fotos. As imagens são ainda complementadas por hashtags, comentários, emojis, stickers que ampliam a sua potência comunicativa. Esse novo ato fotográfico indica, portanto, que as imagens são vetores de comunicação, não tanto pela sua qualidade imagética, mas pelos metatextos que ampliam sua força comunicativa. Os metatextos aliam à imagem outras imagens, comentários, legendas e/ou geolocalização. No caso do Instagram, essa transformação está vinculada a uma prática de dado (LUPTON, 2016) envolvida na composição seja de uma publicação na galeria ou no Stories (legendas, emojis, hashtags, localização...).

O presente artigo é ainda uma contribuição ao dossiê temático "Entretenimento e vida cotidiana: narrativas e consumo". A prática fotográfica no Instagram, bem como em outras plataformas digitais, é um fenômeno planetário, sendo uma das mais fortes expressões da cultura do entretenimento digital. Mais do que uma forma de congelamento de momentos solenes, a produção e a circulação de imagens digitais em redes sociais é uma narrativa cotidiana, fluida e efêmera de si. Como mostraremos nesse artigo, em meio a uma cultura do entretenimento e do consumo de imagens, o objetivo da fotografia no Instagram é ser um vetor de comunicação, de compartilhamento de

\footnotetext{
${ }^{3}$ A pesquisa que dá origem a esse artigo foi realizada como um trabalho de conclusão de curso (TCC) de Catarina Sena sob a orientação de André Lemos.
} 
momentos banais do dia a dia. A "galeria" é uma espécie de reserva temporal, "guardando momentos especiais". Já o Stories se caracteriza por narrativas efêmeras, capturando imagens para o puro entretenimento, "feitas para sumir".

\section{Celulares e redes sociais de fotografias}

Os smartphones estão no centro da mudança social na prática da fotografia. Antes, a tecnologia digital já havia facilitado o processo de produção e circulação de imagens com câmeras e arquivos digitais, mudando a fase analógica de uso de filmes e posterior revelações. O surgimento das redes sociais amplia sobremaneira essa potência. Hoje, os smartphones são os equipamentos mais utilizados para fazer fotografias no mundo ${ }^{4}$, e as redes sociais dedicadas à fotografia o local por excelência para a circulação das mesmas (FLICKR BLOG, 2016; INSTAGRAM BLOG, 2017; LENSVID, 2017). O telefone celular transforma-se em um "aparelho fotográfico universal" (GUNTHERT, 2014).

A fotografia não é mais (apenas) uma prática para o registro de imagens em momentos solenes e especiais (BOURDIEU, 1965), mas vetor de comunicação com a banalização tanto da produção quanto da distribuição de fotos. Não importa mais o "momento único", nem a qualidade técnica da imagem, mas sim o compartilhamento de momentos através dessas imagens. Pode-se falar agora de um novo "processo fotográfico" (PASTOR, 2016). A fotografia transforma-se, segundo Gunthert (2014), em uma imagem fluida e conversacional através das redes sociais. Para ele, o grande valor da imagem é o de ser compartilhada. E esse compartilhamento não é apenas da imagem, mas de uma série de metatextos a partir de uma nova "prática de dados" (LUPTON, 2016) nas redes sociais, reforçando seu caráter comunicativo, social, locativo (LEMOS, PASTOR, 2018, no prelo) ${ }^{5}$.

\footnotetext{
${ }^{4}$ Podemos dizer que esse processo começa com o automatismo inaugurado pela Kodak em 1888 cujo slogan era: "Você aperta o botão, nós fazemos o resto". Com isso vemos nascer a popularização das câmeras fotográficas, gerando uma nova prática fotográfica. Ver Lemos e Pastor (2014).

${ }^{5}$ Os metatextos (localização, comentários, hashtags) são fundamentais nas práticas de circulação de fotografias nas redes sociais, particularmente no Instagram. Interessante apontar que as atualizações recentes do Instagram passaram a permitir que hashtags sejam também seguidas, como se fossem perfis.
} 
As redes sociais digitais ${ }^{6}$ transformam os processos comunicacionais, sociais e informacionais e a prática fotográfica não ficará fora dessa tendência. Nos oito anos que separam o surgimento da primeira rede de compartilhamento de imagens (Fotolog) do Instagram, a prática de compartilhamento de fotografia se ampliou ${ }^{7}$ e uma verdadeira rede foi montada, passando pelos smartphones, o uso de aplicativos específicos, diferentes formatos colaborativos, edições de imagens. Essas plataformas de compartilhamento são áreas centrais de circulação efêmera de conteúdos fotográficos. A efemeridade se dá tanto pelo fluxo de imagens nas timelines, como em áreas de compartilhamento temporário, que surgiram com o Snapchat em 2011.

A principal característica das redes sociais é colocar a fotografia em fluxo de troca permanente, seja em uma galeria pessoal, seja em áreas de armazenamento temporário cuja imagem desaparece depois de um determinado tempo. Diferente da imagem guardada em álbuns pessoais para sempre, exibidos em momentos solenes, temos, com a foto digital e as redes sociais, um novo regime fotográfico, mais popular, massivo e personalizado. As redes sociais de fotografia possibilitam a ampliação da comunicação pela disseminação de imagens com circulação planetária e imediata. Elas oferecem ainda formas de edição com filtros pré-configurados e stickers, podendo ser acompanhadas por legendas, \#hashtags e comentários diversos. As redes sociais mais relevantes nesse domínio são Fotolog ${ }^{8}$ (2002), Flickr (2004), 500px ${ }^{9}$ (2009), Pinterest $^{10}$ (2010) e Instagram ${ }^{11}$ (2010). O Instagram é atualmente a terceira rede social mais

\footnotetext{
${ }^{6}$ Nos referimos a "rede social", no decorrer deste trabalho, como redes sociais na internet. Ver Recuero (2009).

7 Segundo essa pesquisa, seriam 500 milhões de usuários ativos por dia. Disponível em: $<$ https://g1.globo.com/tecnologia/noticia/instagram-tem-800-milhoes-de-usuarios-ativos-por-mes-e-500milhoes-por-dia.ghtml> Acesso em: 01 outubro 2017.

${ }^{8}$ Sistemas de edição ou armazenamento de fotos como Picasa e Google Photos não foram incluídos neste histórico.

${ }^{9}$ Consideramos esta rede relevante pelo foco dado à experiência da fotografia e pelo número de usuários ativos divulgados, ainda que estes estejam consideravelmente abaixo da média das outras redes.

${ }^{10}$ O Pinterest foi incluído nesta lista pela popularidade em usuários ativos e por basear-se no compartilhamento de imagens, ainda que não apresente como central a atividade de produção autoral das mesmas.

11 Ver "8 redes sociais para amantes de fotografia". Disponível em: <https:/canaltech.com.br/redessociais/8-redes-sociais-para-amantes-de-fotografia/>. Acesso em: 17 junho 2017. Ver também: "Origin Stories of six Social Media Giants". Disponível em: <https://www.mightycall.com/blog/adapting-tochange/>. Acesso em: 03 agosto 2017.
} 
popular no mundo, com mais de 800 milhões de usuários mensais ${ }^{12}$, atrás somente do Facebook e do YouTube ${ }^{13}$. O quadro abaixo (Quadro 1) faz uma comparação entre as principais redes sociais de fotografia. Vamos concentrar a descrição na rede aqui analisada, a mais importante atualmente, o Instagram.

\begin{tabular}{|l|l|l|l|l|l|l|}
\hline Rede Social & $\begin{array}{l}\text { Média de } \\
\text { Usuários } \\
\text { (milhões) }\end{array}$ & Imagens & Uso & Plataforma & Interação ${ }^{\text {14 }}$ & $\begin{array}{l}\text { Áreas } \\
\text { Temporárias }\end{array}$ \\
\hline Fotolog & 33 & Foto & Pago/gratuito & Web & Comentários, Curtir & Não \\
\hline Flickr & 122 & $\begin{array}{l}\text { Foto/ } \\
\text { vídeo }\end{array}$ & Pago/gratuito & $\begin{array}{l}\text { Web/ } \\
\text { móvel }\end{array}$ & $\begin{array}{l}\text { Grupos, } \\
\text { Comentários, } \\
\text { Favoritar }\end{array}$ & Não \\
\hline $\mathbf{5 0 0 p x}$ & 12 & Foto & Pago/gratuito & Web/ móvel & $\begin{array}{l}\text { Compra e venda } \\
\text { Não }\end{array}$ & Nán \\
\hline Pinterest & 175 & Foto & Gratuito & Web/móvel & “Pinar", bate-papo & Não \\
\hline Instagram & 800 & $\begin{array}{l}\text { Foto e } \\
\text { vídeo }\end{array}$ & Gratuito & Móvel & $\begin{array}{l}\text { Curtir, comentar, } \\
\text { bate-papo }\end{array}$ & Sim \\
\hline
\end{tabular}

Quadro 1: Principais características das redes sociais imagéticas até o Instagram.

\section{Instagram}

O Instagram foi criado pelo brasileiro Mike Krieger e pelo estadunidense Kevin Systrom em outubro de 2010, inicialmente apenas para o sistema operacional da

12 Dados apontavam 700 milhões. Disponível em: <https://www.dreamgrow.com/top-15-most-popularsocial-networking-sites/> Acesso em: 03 agosto 2017. Dados mais recentes apontam para mais de 800 milhões. Disponível em: < https://instagram-press.com/our-story/> Acesso em: 01 agosto 2018.

${ }^{13}$ Não considerando os mensageiros WhatsApp e Messenger. Ver "How many people use social media?" Disponível em: < http://expandedramblings.com/index.php/how-many-people-use-social-media/> Acesso em: 03 agosto 2017.

14 A interação entre usuários foi limitada às publicações e chat. Os "grupos" criados para enviar mensagens privadas estão dentro do bate-papo. Já salvar imagens favoritas em galerias é uma ação privada de quem salva. As buscas agregadas são uma função que o Instagram criou, agrupando publicações num mesmo lugar para quem busca esses dados. A mesma lógica está na possibilidade de etiquetagem (tags) com hashtags e geolocalização. Há várias funcionalidades que não são exatamente o que entendemos por essa "interação entre usuários": stickers associados a lugares específicos, filtros promocionais produzindo conteúdo intermídia, novos usos de realidade aumentada, possibilidade de fazer enquetes no Stories. Essas são funcionalidade que remetem para interação, mas destacamos aqui uma interação mais direta. 
Apple $^{15}$. Em abril de 2012, mesmo mês em que foi adquirido pela Facebook Inc. ${ }^{16}$, passou a funcionar também com o sistema Android. A função de publicação de vídeos surge somente em junho de 2013. Nesse mesmo ano, a plataforma lança o Direct, aba de bate-papo privado. Em junho de 2014, o aplicativo, que até então oferecia apenas filtros para a modificação das fotos, anunciou ${ }^{17}$ uma atualização que incluía diversos ajustes e modificações como brilho e contraste. Em agosto de 2015, passam a ser permitidas imagens verticais e horizontais que antes eram restritas à forma quadrada ${ }^{18}$.

As interações se davam somente através de likes (curtidas) e comentários. Em novembro do mesmo ano, torna-se compatível com aparelhos de sistema operacional Windows Phone. Os perfis podem ser públicos ou privados e são compostos pelo nome do usuário, uma descrição opcional de até 150 caracteres e álbum das imagens compartilhadas com seus respectivos seguidores. As imagens podem ser acompanhadas de legendas e é possível vincular sua publicação a uma localização. As publicações se dão exclusivamente a partir de dispositivos móveis, mas desde fevereiro de 2013 é possível acessá-las pela $w e b^{19}$.

Em março de 2016, a empresa anunciou ${ }^{20}$ que a página inicial (feed) deixaria de exibir as imagens publicadas por ordem cronológica, priorizando conteúdos nos quais cada usuário supostamente estaria mais interessado. A justificativa foi de que as pessoas deixam de ver aproximadamente $70 \%$ das imagens compartilhadas pelos perfis que seguem. Em maio de 2016, a companhia apresentou a primeira mudança de ícone ${ }^{21}$ e,

\footnotetext{
15 Ver "A nação do Instagram (governada por um brasileiro)". Disponível em: $<$ http://veja.abril.com.br/tecnologia/a-nacao-do-instagram-governada-por-um-brasileiro/\#> Acesso em 24 maio 2017.

16 "De longe, é o mais alto valor pago até o momento pela compra de um sistema/aplicativo dedicado a funcionar em plataformas móveis”. (SILVA JUNIOR, 2014, p. 2). Sobre Instagram e Facebook, ver Carrera (2012). Sobre Facebook ver Correia (2012).

17 Disponível em: <http://blog.instagram.com/post/87703266532/new-creative-tools > Acesso em: 13 julho 2017.

18 Disponível em: < https://canaltech.com.br/redes-sociais/adeus-quadrado-instagram-agora-permitefotos-verticais-e-horizontais-48185/> Acesso em: 13 julho 2017.

19 Ver "Feed do Instagram agora pode ser acessado online". Disponível em: $<$ http://link.estadao.com.br/noticias/geral,feed-do-instagram-agora-pode-ser-acessadoonline,10000034193> Acesso em: 24 maio 2017.

${ }^{20}$ Disponível em: < http://blog.instagram.com/post/141107034797/160315-news> Acesso em: 24 maio 2017.

21 Ver "The inside story behind Instagram's original app icon, which was designed in 45 minutes". Disponível em: <http:/www.businessinsider.com/the-inside-story-behind-instagrams-original-app-iconwhich-was-designed-in-45-minutes-2016-5> Acesso em: 03 julho 2017.
} 
em agosto, lançou uma atualização com a função Stories. Esta consiste na publicação de imagens (fotos e vídeos) que se apagam automaticamente em 24h. O Instagram é a única rede social imagética que tem uma área de armazenamento temporário, como o Snapchat (REBOUÇAS, MENEZES, 2016) ${ }^{22}$.

\section{Plataformas com área de armazenamento temporário: o caso do Instagram}

Armazenamento temporário é o local, nos sistemas de compartilhamento de fotografias, onde as imagens se apagam, automaticamente, $24 \mathrm{~h}$ depois de publicadas. Esse formato tem sido tendência entre as maiores redes sociais do mundo. Embora possamos dizer que a circulação das fotografias e vídeos em redes sociais já esteja sob o signo da efemeridade com o trânsito em timelines, esse novo formato amplia ainda mais esse regime. Esse fenômeno foi popularizado pelo aplicativo Snapchat $(2011)^{23}$ e hoje ele está presente em também no WhatsApp, Facebook, Messenger e Instagram ${ }^{24}$.

Em abril de 2017, o Instagram Stories ultrapassou o Snapchat ${ }^{25}$ com o número de 200 milhões de usuários ativos por dia (em janeiro eram 150 milhões). O Snapchat

\footnotetext{
22 Sobre as mudanças no Instagram, ver "Instagram 2.0 Out Now, With A Plethora Of New Features". Disponível em: <http://www.mactrast.com/2011/09/instagram-2-0-out-now-with-a-plethora-of-newfeatures/> Acesso em: 07 julho 2017. Ver também "Instagram cria ordem de relevância no feed de fotos, igual ao Facebook". Disponível em: <http://www.techtudo.com.br/noticias/noticia/2016/03/instagramadota-ordem-de-relevancia-no-feed-estilo-facebook.html $>$ Acesso em: 04 maio 2017. Ver ainda "Instagram: rede social para compartilhar fotos e vídeos". Disponível em: $<$ http://www.techtudo.com.br/tudo-sobre/instagram.html $>$ Acesso em: 01 agosto 2017. Ver "Odiou o novo feed do Instagram? Sete opções para trocar a rede social". Disponível em: $<$ http://www.techtudo.com.br/listas/noticia/2016/06/odiou-o-novo-feed-do-instagram-sete-opcoes-paratrocar-rede-social.html> Acesso em: 04 junho 2017.

${ }^{23}$ O Snapchat foi o primeiro aplicativo gratuito de fotografia para dispositivos móveis com armazenamento temporário. Com a função "Minha História", lançada em outubro de 2013, fotos e vídeos compõem uma sequência de cenas que contam a história do dia de cada perfil. Há também a função "Histórias ao Vivo" que permite o acesso a vídeos enviados por usuários e selecionados pela. Ver "Instagram Stories enfim copia as máscaras do Snapchat". Disponível em https://tecnoblog.net/214745/instagram-stories-mascaras/. Acesso em 19 de julho de 2017. "Snapchat lança quatro novidades contra Instagram Stories e outros rivais". Disponível em http://www.techtudo.com.br/listas/2017/05/snapchat-lanca-4-novidades-contra-instagram-stories-eoutros-rivais.ghtml. Acesso em: 03 de agosto de 2017. Ver também Monteiro e Mazzili (2016).

${ }^{24}$ Ver "Stories no Instagram, Facebook e WhatsApp: tudo sobre as fotos que somem". Disponível em http://www.techtudo.com.br/listas/2017/05/instagram-stories-vs-whatsapp-status-tudo-sobre-as-fotos-quedesaparecem.ghtml. Acesso em 23 de julho de 2017.

${ }^{25}$ http://www.tudocelular.com/android/noticias/n91491/instagram-stories-ultrapassa-usuarios-

snapchat.html. Acesso em 03 de maio de 2017.
} 
informou $^{26}$ em fevereiro deste mesmo ano ter 158 milhões de usuários diários nas publicações de fotos e vídeos, número que, segundo a própria rede social, teria se mantido até o mês de abril. Desde o lançamento do Instagram Stories, o Snapchat segue investindo em novidades. Em maio de 2017, por exemplo, uma atualização veio oferecer recurso de vídeo animado em looping, semelhante ao Boomerang, além de pincel para desenhar com emojis e ferramenta de borracha para desfazer desenhos, tendo esta última já sido reproduzida pelo Instagram no mesmo mês. O quadro abaixo (Quadro 2) faz uma síntese dessas redes ${ }^{27}$.

\begin{tabular}{|l|l|l|l|l|l|l|}
\hline Nome & $\begin{array}{l}\text { Média de } \\
\text { Usuários } \\
\text { (milhões) }\end{array}$ & Imagens & Acesso & Plataforma & Interação & $\begin{array}{l}\text { Áreas } \\
\text { Temporárias }\end{array}$ \\
\hline Snapchat & 166 & Foto & Gratuito & Móvel & $\begin{array}{l}\text { Resposta às imagens; enviar } \\
\text { diretamente }\end{array}$ & Sim \\
\hline $\begin{array}{l}\text { Instagram } \\
\text { Stories }\end{array}$ & 250 & Foto/vídeo & Gratuito & Móvel & $\begin{array}{l}\text { Resposta às imagens; enviar } \\
\text { diretamente; marcar perfis, } \\
\text { realizar live em parceria }\end{array}$ & Sim \\
\hline $\begin{array}{l}\text { WhatsApp } \\
\text { Status }\end{array}$ & 175 & Foto/vídeo & Gratuito & Móvel & Resposta às imagens & Sim \\
\hline $\begin{array}{l}\text { Facebook } \\
\text { Stories }\end{array}$ & 250 & Foto/vídeo & Gratuito & Móvel & $\begin{array}{l}\text { Resposta às imagens; enviar } \\
\text { diretamente }\end{array}$ & Sim \\
\hline
\end{tabular}

\footnotetext{
26 Disponível em: <http://link.estadao.com.br/noticias/empresas,snapchat-tem-158-milhoes-de-usuariosativos-diariamente,70001651159> Acesso em: 03 maio 2017.

${ }^{27}$ As principais diferenças entre eles estão nas interfaces e nas possibilidades de modificação de imagens. Diferente do Snapchat e do Instagram Stories, nos quais se pode, por exemplo, fazer uma transmissão ao vivo ou criar vídeos rebobinados, as modalidades de captura em tempo real no Meu Dia (Messenger), Facebook Stories e WhatsApp Status são simplesmente foto e vídeo. Há uma variação no que diz respeito ao acesso ao rolo da câmera do dispositivo utilizado e à apresentação da passagem de tempo. As opções de configuração de privacidade são semelhantes, podendo o usuário sempre ocultar seu conteúdo de perfis específicos. Em todos os aplicativos é possível interagir respondendo às imagens dos contatos e ter acesso a quem visualizou seu conteúdo. Ver "Facebook lança Messenger Day, após WhatsApp Status e Instagram Stories". Disponível em: <http://www.techtudo.com.br/noticias/noticia/2017/03/facebooklibera-messenger-day-para-todos-um-novo-rival-para-o-snapchat.html> Acesso em: 07 junho 2017. Ver também: "Facebook vs Snapchat: um resumo da guerra entre Stories e Snaps". Disponível em: $<$ http://www.techtudo.com.br/noticias/2017/05/facebook-vs-snapchat-um-resumo-da-guerra-entre-storiese-snaps.ghtml> Acesso em 01 junho 2017. Ver ainda "WhatsApp ganha recursos do Snapchat e Instagram Stories". Disponível em: <http://exame.abril.com.br/tecnologia/whatsapp-ganha-recursos-do-snapchat-einstagram-stories/> Acesso em: 22 junho 2017.
} 
Quadro 2: Principais características das plataformas com área de publicação temporária.

\section{O Instagram Stories}

O Instagram Stories, assim como o modo "Minha História" do Snapchat, permite ao usuário compartilhar imagens por $24 \mathrm{~h}$. A ideia é que se forme uma narrativa do dia, com imagens que podem ser produzidas diretamente a partir da tela de captura, ou do rolo da câmera do dispositivo móvel, sendo possível salvá-las no dispositivo. As capturas de imagem em tempo real através da câmera do Instagram Stories (figura 1) ${ }^{28}$ podem ser feitas nos modos "Normal" (ao tocar o botão de captura da tela se faz uma foto e segurando o mesmo se faz um vídeo de até 16 segundos); "Boomerang" (sequência de fotos em formato de vídeo animado); "Mãos livres" (vídeo sem que o botão de comando precise estar pressionado) e "Ao vivo" (em tempo real e que podem ser salvas). Em maio de 2017 foi incluída a opção "rebobinagem", que captura vídeo e imediatamente o disponibiliza de trás para frente, sem som.

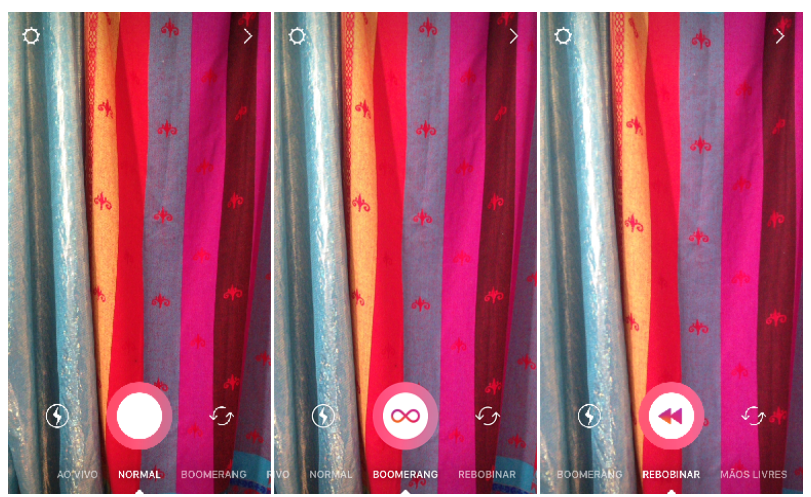

Figura1: Páginas da câmera do Instagram Stories em diferentes modos de captura

Atualmente são onze as possibilidades de edição com filtros (figura 2) que podem ser testados ao deslizar o dedo pela tela. Diferente do precursor Snapchat, no

\footnotetext{
28 Todas as imagens são de acervo pessoal, a não ser quando indicado diferentemente.
} 


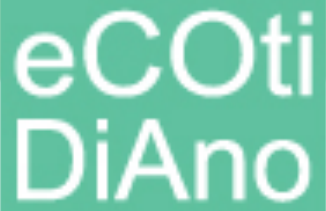

\section{PPGMC}

Instagram Stories as alterações de filtro só podem ser feitas após o registro e não durante a captura da imagem.

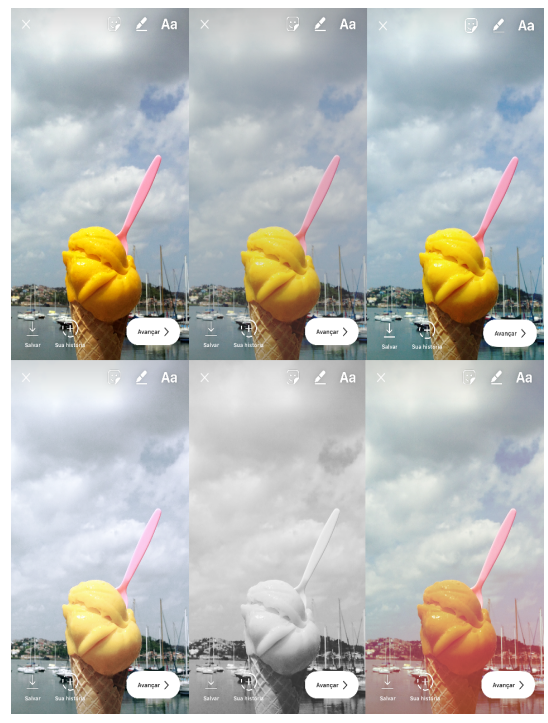

Figura 2: Os filtros básicos do Instagram Stories sobre uma mesma foto

A edição permite ainda inserir sobre a imagem textos e quaisquer figuras do teclado de emojis (figura 3) do dispositivo, ou adesivos que o aplicativo oferece, permitindo, em atualização recente, inserir GIFS. Estes vão de figuras de chapéus, óculos e outros acessórios até os pacotes de stickers temáticos, pautados em feriados e datas comemorativas, a exemplo de imagens para Páscoa e Dia das Mães (figura 4). Há também as ilustrações com marcação de temperatura, horário e localização geográfica do dispositivo.

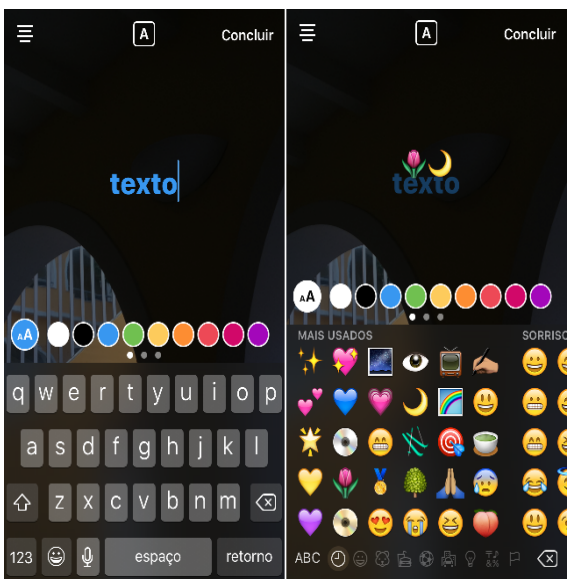

Figura 3: Telas de adição de texto à imagem no Instagram Stories 


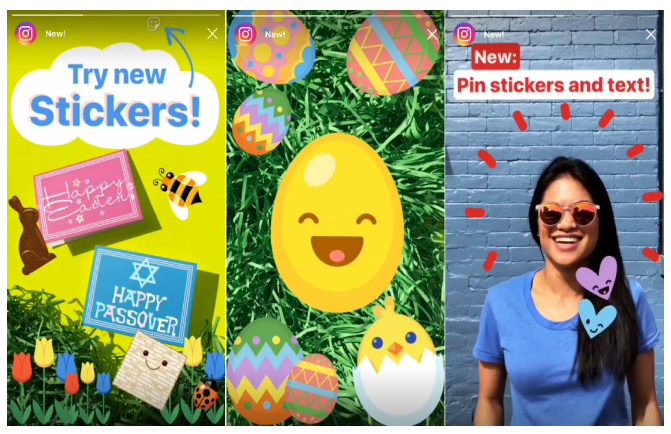

Figura 4: Divulgações de atualizações de stickers no Instagram Stories

Uma função original do Instagram Stories é a selfie ${ }^{29}$ sobreposta à imagem ("selfie sticker"), que chegou ao aplicativo em abril de 2017 junto com a possibilidade de fixar figuras e adesivos sobre objetos e superfícies, no caso dos vídeos (figura 5). Em maio de 2017, o Instagram incluiu à câmera do Stories as opções de filtros animados com máscaras para foto e vídeo (figura 6).

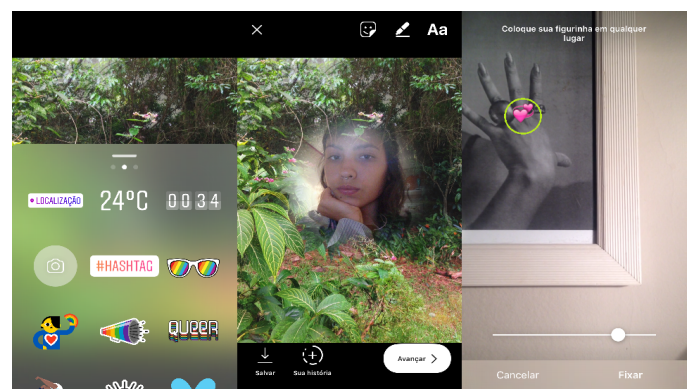

Figura 5: Telas (stickers e indicadores; selfie sobreposta à imagem; emoji sobre objeto em vídeo)

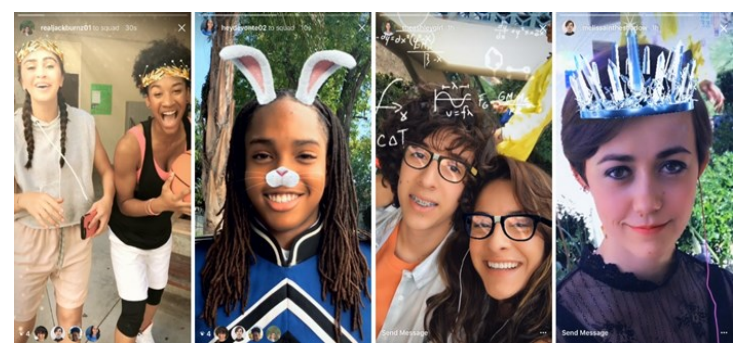

Figura 6: Filtros de máscaras do Instagram Stories. Fonte: https://goo.gl/a5ahG7

\footnotetext{
${ }^{29}$ Ver "Instagram launches selfie filters, copying the last big Snapchat feature". Disponível em: $<$ https://techcrunch.com/2017/05/16/instagram-face-filters/> Acesso em: 22 julho 2017.
} 


\section{e

O Stories inaugura uma nova dinâmica com o espaço de bate-papo do Instagram (opção "Escreva uma mensagem"). Quando publicadas na opção "Sua história", as fotos e vídeos do Instagram Stories são disponibilizados de forma pública ou privada, a depender das configurações de privacidade. As atualizações de publicação são expostas no topo da página inicial (figura 7). É possível ocultar o conteúdo de usuários específicos. Há a possibilidade de enviar diretamente foto ou vídeo somente para uma ou algumas pessoas. Nesse caso, o usuário destinatário pode visualizar o conteúdo duas vezes, durante até quatro segundos por vez.

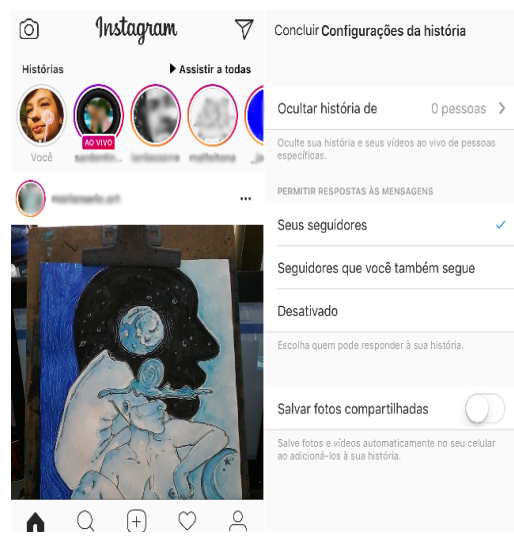

Figura 7: Página inicial do Instagram e de configurações de privacidade do Stories

\section{Análise do uso da Galeria e dos Stories}

Investigamos comparativamente o uso da galeria e do Stories do Instagram a partir de uma enquete respondida por 173 usuários, dos quais 19 adicionaram comentários abertos (espontâneos) sobre o uso que fazem da rede social ${ }^{30}$. O questionário online $^{31}$ esteve disponível entre 29 de junho e 09 de julho de 2017. Para análise posterior e para confrontar com resultados da pesquisa, acompanhamos e armazenamos capturas de tela e conteúdos compartilhados por sete dias de três pessoas que demonstraram, nos comentários, interesse em participar mais profundamente da pesquisa. O principal critério de escolha dessas usuárias $^{32}$ foi a frequência $^{33}$ de

\footnotetext{
${ }^{30}$ Até o final da enquete não foi identificada nenhuma pesquisa similar.

${ }^{31}$ Divulgado por páginas pessoais no Facebook.

${ }^{32}$ Mulheres entre 22 e 31 anos, condizendo com o perfil mais ativo nas respostas ao questionário.

${ }^{33}$ As interessadas em continuar participando da pesquisa deixaram no questionário seus respectivos nomes e contatos, tornando possível a busca por seus perfis no Instagram. As informações têm aqui uma função ilustrativa e não representativa.
} 
publicação nos perfis. Após contato por e-mail, elas foram convidadas para uma entrevista $^{34}$ via WhatsApp ${ }^{35}$.

A maioria dos respondentes, 74,6\%, disse residir na região Nordeste do Brasil, sendo $75,7 \%$ do sexo feminino. A maioria, $63,3 \%$, tem entre 22 e 31 anos de idade e são portadores de diplomas de ensino superior (58,5\%). Metade diz estar há 4 ou 5 anos no Instagram. Esses dados estão de acordo com recente pesquisa da Pew Reseach Center nos Estados Unidos que aponta que no Instagram, 60\% dos usuários são do sexo feminino, $51 \%$ têm entre 18 e 29 anos e $71 \%$ têm curso superior ou pós-graduação ${ }^{36}$.

Sobre produção e compartilhamento, $18,5 \%$ disseram não utilizar o Stories. A frequência de publicação teve, nos dois espaços do Instagram, respostas bem diversas. No entanto, pode-se notar que o compartilhamento no Stories tende a ser mais frequente. As fotografias mais compartilhadas são feitas pelos próprios usuários, seguidas por vídeos autorais. No caso destes, são expressivamente mais publicados no Stories $(76,6 \%)$, sugerindo uma nova relação do usuário do Instagram com o vídeo, colocado agora em regime de circulação temporária. No Stories, há maior tendência de reproduzir conteúdos de outras páginas e pessoas (34.8\%), enquanto que na galeria somente $8,1 \%$ fazem isso.

O compartilhamento no Stories costuma ser feito imediatamente $(67,4 \%)$, enquanto que na galeria esse percentual é de apenas 11,6\%. Isso mostra que as imagens mais impulsivas tendem a ser direcionadas ao Stories. No Stories, as imagens são editadas por $80 \%$ (48,2\% às vezes e $31,9 \%$ sempre), sendo esse número menor na galeria $(70,5 \%$, sendo $36,4 \%$ eventualmente e $34,1 \%$ sempre). No Stories, a sobreposição de texto e imagem é a opção mais comum $(87,7 \%)$. Trata-se, de uma forma de ampliar a capacidade informacional da imagem, incluindo explicações, mensagens, expressões textuais sobrepostas (figura 8) às fotos e vídeos. Essa prática

\footnotetext{
${ }^{34}$ Foi feita a pergunta padrão "Como você costuma diferenciar os conteúdos que vão para cada um dos ambientes? Há critérios que você identifica nesse processo?". Além disso, foi pedido que falassem um pouco mais sobre opiniões próprias deixadas nos comentários no questionário.

${ }^{35}$ Ao longo deste capítulo algumas das imagens são utilizadas, com devida autorização das participantes, que são aqui representadas pelos nomes fictícios Ana, Joana e Maria.

36 Ver News Use Across Social Media Platforms 2017. Disponível em: $<$ http://www.journalism.org/2017/09/07/news-use-across-social-media-platforms-

2017/?utm_content=buffer16756\&utm_medium=social\&utm_source=twitter.com\&utm_campaign=buffe r > Acesso em: 24 janeiro 2017.
} 


\section{míDiA \\ eCOti

reforça a hipótese de que as fotografias na era das redes sociais ganham capacidade comunicacional com os metatextos. Já na área de publicação permanente, esse metatexto aparece na legenda da foto (figura 9).

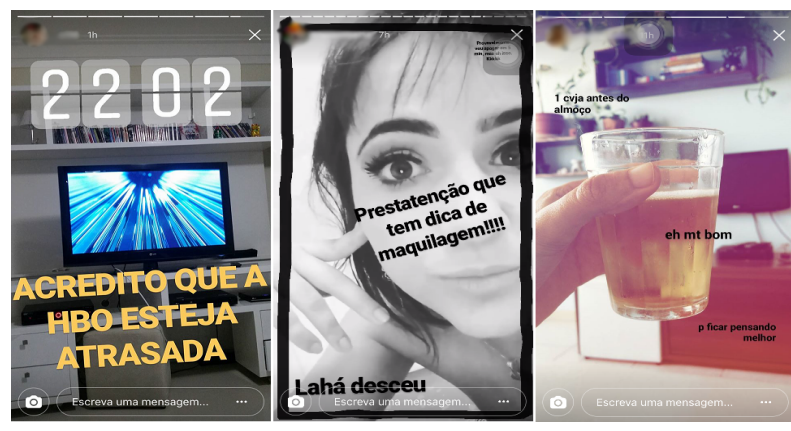

Figura 8: Imagens com sobreposição de texto no Instagram Stories

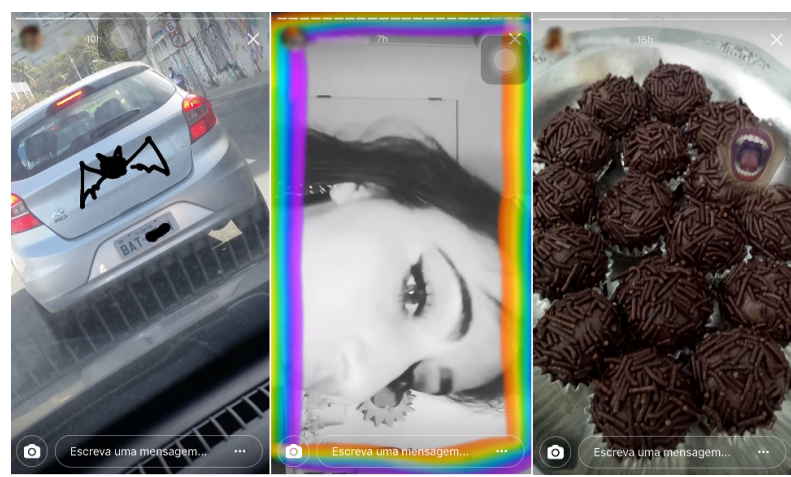

Figura 9: Imagens com uso de pincel para desenhar, pincel "arco-íris" e selfie sticker, no Instagram Stories

O Stories pode ser usado ainda como ferramenta de modificação de imagem. A publicação abaixo foi feita na galeria do perfil de Ana, que disse ter usado um dos pincéis do Stories para desenhar os traços em branco e posteriormente salvado a imagem (figura 10) no smartphone. 


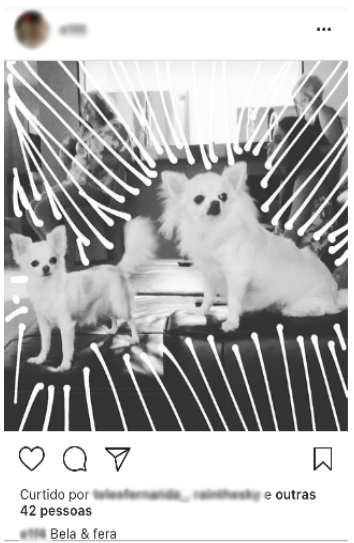

Figura 10: Imagem modificada no Stories e publicada na galeria de um perfil no Instagram

Os conteúdos compartilhados são mais diversos no Stories (20\% a mais do que na galeria). Enquanto "paisagens" foi a opção mais selecionada na galeria, as selfies lideraram o Stories. Se relacionado aos comentários deixados no questionário sobre "relevância" e "importância"37, o fato de as selfies serem o principal conteúdo no Stories pode revelar certo conforto entre a associação da autoexposição, da banalidade e da temporalidade (PERSICHETTI, 2013). No entanto, esse não é um diferencial entre os dois ambientes, pois as selfies foram o segundo conteúdo mais selecionado sobre o uso da galeria.

A apresentação de si mesmo na internet (SIBILIA, 2008, SILVA, 2010) é uma tônica nas redes sociais, não apenas naquelas dedicadas à fotografia. No caso do Stories, o "eu" como conteúdo imagético se fez presente nas opções adicionadas ao questionário como: "eu cantando" e "eu, mas não selfie". A maior produção de conteúdo imagético no Stories se dá na própria casa do usuário, enquanto que na galeria a mesma acontece mais no espaço público. Uma respondente diz que saber que as imagens se apagarão em $24 \mathrm{~h}$ a deixa menos preocupada em relação à sua privacidade, ou com o que as pessoas vão pensar. Por mais que as noções de "público" e "privado" apresentem constantes transformações, podemos inferir que o conteúdo mais íntimo é escolhido para ser o mais volátil.

\footnotetext{
${ }^{37}$ Disponíveis na página 19.
} 
"Costumo usar o Stories para postar coisas de rotina sem muita preocupação estética", diz um dos respondentes. Com a exposição temporária das imagens, mais da metade dos participantes sentem-se "mais à vontade para experimentar (ex.: ângulos, enquadramentos, zoom, ferramentas de edição)" (54,7\%) e "menos apegada (o) ao cuidado com a qualidade (luz, resolução etc.) das imagens" (53,2\%), reforçando o teor comunicacional das imagens fotográficas em redes sociais hoje.

Outra respondente afirma sentir-se menos preocupada com sua privacidade ou com o que as pessoas vão pensar. Esses e outros exemplos relacionam o uso do Stories a um método de publicação menos "preocupado", tanto em termos de "relevância" de conteúdo como de "qualidade" de imagem ${ }^{38}$. "Mais livre para publicar coisas corriqueiras que não são relevantes o suficiente para estar no meu feed, mas que de alguma forma mostram quem eu sou e o que eu gosto", diz uma outra opinião.

A incorporação do Stories pelo Instagram tem levado a um abandono gradual da plataforma Snapchat. Antes do Instagram Stories, 32,2\% dos respondentes usavam o Snapchat. Agora, são apenas $8,8 \%$. A chegada do Stories é a tendência de expansão do compartilhamento temporário. Tendo em vista que a maior parte dos participantes está no Instagram há quatro ou cinco anos, é bem provável que acumulem seguidores e conexões e, assim, evitem usar dois sistemas diferentes para a mesma funcionalidade. Outro fator é a possibilidade de vinculação da conta do Instagram à do Facebook, o que torna ainda mais provável a escolha por um único sistema ${ }^{39}$. A pesquisa indica esse abandono gradual do Snapchat, embora não possamos afirmar e generalizar essa afirmação. No entanto, há uma relação mais forte com o compartilhamento temporário a partir do Stories, apontando para novos usos e práticas de compartilhamento de imagens nas redes sociais.

Há ainda outros elementos de diferenciação na forma como o usuário se sente ao publicar uma imagem na galeria ou no Stories. A expectativa pelo "like" e a relação

\footnotetext{
${ }^{38}$ Recentemente o Stories lançou a ferramenta de enquetes com a o usuário pode colocar stickers de enquetes que são disponibilizam os resultados em tempo real. Ver "Instagram Stories lança ferramentas de enquetes". Disponível em: $<$ https://brasil.elpais.com/brasil/2017/10/03/tecnologia/1506996038_745281.html> Acesso em: 11 junho 2017.

${ }^{39}$ Ver "Ações da Snap chegam a cair mais de $10 \%$ e atingem nível mais baixo desde estreia na bolsa". Disponível em: <http://g1.globo.com/tecnologia/noticia/acoes-da-snap-chegam-a-cair-mais-de-10-eatingem-nivel-mais-baixo-desde-estreia-na-bolsa.ghtml> Acesso em: 11 julho 2017.
} 
direta do Stories com as mensagens privadas são alguns deles. Enquanto as publicações da galeria podem ser curtidas e comentadas publicamente, no Stories a única possibilidade de reação às imagens ${ }^{40}$ é direcionada para o Direct, a seção de bate-papo, de interação direta e privada entre usuários. Segundo alguns respondentes:

Eu me sinto à vontade para responder as histórias das pessoas, o que gera conversas até substanciais! Adoro receber também. São ótimas formas de puxar assunto com alguém que você quer conversar, mas não sabe como. Ou ate mesmo de lembrar de um amigo e mostrar que se importa. Criar assunto e abertura para conversar com os seguidores, conhecer pessoas novas que tenham o mesmo interesse cotidiano que o meu. A opção de Stories no Instagram possibilitou uma aproximação dos profissionais que eu sigo, bem como conhecer pessoas novas e que tenham interesse parecido comigo. Já conheci um rapaz com quem me relacionei, já fiz amizades e contatos profissionais também usando a ferramenta de mensagem "Direct".

\section{Conclusão}

O Instagram tem no seu nome a palavra instantâneo. A presença e o uso do Stories são hoje uma comprovação de que as noções de instantaneidade no compartilhamento de imagens estão em constante movimento. As redes sociais com área de armazenamento temporário, por aliarem mobilidade, simplicidade na modificação das imagens e circulação imediata destas, são uma manifestação expressiva da cultura da efemeridade (LIPOVETSKY, 1987).

Há uma urgência em produzir conteúdo novo e atrativo. Uma vez equipados e conectados, isso faz de todos, na atual cultura digital, produtores e emissores de informação. A circulação faz apologia da participação. A performatividade dos algoritmos nos aplicativos, nas redes sociais e nos smartphones amplia a circulação de imagens fotográficas, e faz com que essas imagens desempenhem uma ampla agência comunicacional.

Foram observadas, a partir dos dados do questionário, tendências de como os usuários se comportam diante das diferenças dos dois ambientes. Mostramos como o recurso do Stories, que acaba de completar um ano, modifica as práticas de uso do Instagram, antes baseadas na circulação de imagens nas "galerias". O Stories, pela finitude temporal programada das imagens, funciona como um espaço para exposição

\footnotetext{
${ }^{40}$ Até a atualização que trouxe a ferramenta "enquete".
} 
de "qualquer coisa". Já a galeria é predominante usada para imagens de maior destaque e importância, ainda que elas tenham necessariamente importância em termos de qualidade imagética.

Como exemplo, podemos sintetizar com os olhares das três participantes, Maria, Ana e Joana. Maria afirma que o Stories simboliza o espaço para veicular imagens de momentos fugazes, já a galeria é o lugar para onde vão "os registros do coração". Ana pensa o Stories como um diário, um espaço para registrar coisas interessantes ao longo do dia: "No Stories eu posto sem tanto cuidado, coisas efêmeras mesmo, na galeria quero guardar o melhor do melhor”, conta. Para Joana, o Stories é dedicado a ocasiões efêmeras, superficiais e instantâneas. Ela posta aqui quase que diariamente. A sua relação com a galeria é esporádica e as publicações raramente se dão imediatamente após o registro, pois ela dedica mais tempo editando essas imagens. Se compararmos as capacidades de edição de imagem do Stories e da Galeria, fica claro que o primeiro dispõe de maneiras mais lúdicas e descontraídas de manipulação da imagem (foto e/ou vídeo). As ferramentas do Stories estimulam um uso mais criativo do sistema e isso é amplificado pelas possibilidades de customização e interação.

Guardadas as devidas proporções, e tendo em vista o novo registro temporal das fotografias, podemos dizer, com base nos achados desta pesquisa, que a galeria é uma espécie de reserva de tempo, de manutenção das imagens mais cuidadosamente selecionadas pelo usuário. É o espaço no qual se pode encontrar ainda resquícios dos antigos "álbuns de fotografia" da era analógica. Certamente, não vemos mais rituais cerimoniosos necessariamente associados à prática do registro e da memória, mas nesta área de publicações permanentes persiste a possibilidade de revisitar, a qualquer momento, imagens que, juntas e com o passar dos dias, podem contar uma história. Ela funciona também como uma linha do tempo da vida, já que as fotos são datadas. Ao revisitar a galeria, o usuário pode ver, por exemplo, o que aconteceu no ano, ou em que ano um determinado evento ocorreu.

Já o Stories é o lugar do efêmero, das publicações temporárias. Essa dimensão ganha em potência quando o aplicativo que mais cresce no mundo ${ }^{41}$ incorpora esse

41 Disponível em: <https://brasil.elpais.com/brasil/2017/08/02/tecnologia/1501658806_683191.html> Acesso em 20 agosto 2017 
recurso. Aqui, as informações imagéticas são postas em sequência, durante um dia temporalizadas a partir de uma lógica de início, meio e fim - sob a ótica do apagamento. Se a galeria é a história que se quer guardar, o Stories é o burburinho do dia a dia que deve desaparecer para dar origens aos burburinhos do dia seguinte. Esse burburinho também é amplificado pelo conteúdo extraimagético que o Stories possibilita, bem como pelas suas formas específicas de sociabilidade, como o uso de enquetes, a realização de lives em conjunto com outros usuários, o uso de stickers relacionados a localizações específicas, dentre outros.

Com o Stories, os usuários estão menos preocupados com a "aprovação" dos outros, e isso tende a minimizar rigor nos critérios de seleção dos conteúdos publicados. O compartilhamento caracteriza-se por imagens "mais espontâneas". No Stories, não são momentos especiais para o futuro, mas evento únicos, expressando a dimensão do "aqui e o agora". Na galeria, guarda-se o tempo, mesmo que o feed dê a ela, também, uma certa efemeridade com a circulação do fluxo da informação. Na galeria consuma-se o tempo na circulação e visualização temporária.

O princípio da prática fotográfica em redes sociais, independente do ambiente, continua o mesmo: estar em contato com o outro, compartilhar o espaço e o tempo, o que se está vendo ou fazendo em determinados locais. No caso da galeria, o compartilhamento pode significar "guardar momentos especiais", visto que são imagens "feitas para durar". No caso do Stories, são comumente capturadas cenas "banais", imagens que, embora possam ser salvas, são "feitas para sumir".

A incessante circulação de fotos e vídeos digitais nas redes, e a ampliação da instantaneidade na produção e no compartilhamento destas mídias desafiam nosso entendimento a respeito da experiência de registro e memória, criando uma outra prática fotográfica que merece mais aprofundamento e discussão.

\section{Referências}

BOURDIEU, Pierre. Un art moyen. Paris: Les Éditions de Minuit, 1965.

CARRERA, F. (2012). Instagram no Facebook: uma reflexão sobre ethos, consumo e construção de subjetividade em sites de redes sociais. Animus Revista Interamericana 
de Comunicação Midiática, Santa Maria, v. 11, n. 22, p.148-164, 21 dez. http://dx.doi.org/10.5902/217549776850.

CORREIA, P. M. A. R.; MOREIRA, M. F. R. (2014). Novas formas de comunicação: história do Facebook - Uma história necessariamente breve. Alceu, [s.i.], v. 14, n. 28, p.168-187, abr.

GUNTHERT, André. L'image conversationnelle: les nouveaux usages de la photographie numérique. Études photographiques, v. 31, abr. 2014. Disponível em: $<$ http://etudesphotographiques.revues.org/3387> Acesso em: 31 ago. 2017.

FLICKR BLOG. Smartphones Dominate Flickr Uploads. Disponível em: $<$ http://blog.flickr.net/2016/12/06/smartphones-dominate-flickr-in-2016-apple-leads/> Acesso em: 31 ago. 2017.

INSTAGRAM BLOG. $\mathbf{7 0 0}$ Million. Disponível em: $<$ http://blog.instagram.com/post/160011713372/170426-700million> Acesso em: 31 ago. 2017.

LEMOS, A; PASTOR, L (2014). Internet das coisas, automatismo e fotografia: uma análise pela Teoria Ator-Rede. Famecos: mídia, cultura e tecnologia, Porto Alegre, v. 21, n. 3, p.1016-1040, set. Disponível em: $<$ http://revistaseletronicas.pucrs.br/ojs/index.php/revistafamecos/article/view/18114/125 $74>$

LEMOS, A; PASTOR, L (2018, no prelo). A Fotografia como Prática Conversacional de Dados. Espacialização e sociabilidade digital no uso do Instagram em praças e parques na cidade de Salvador. Revista Comunicação, Mídia e Consumo. SP: ESPM. LENSVID. LensVid Exclusive : What Happened to the Photography Industry in 2016 Disponível em: <https://ensvid.com/gear/lensvid-exclusive-happenedphotography-industry-2016/> Acesso em: 31 ago. 2017.

LIPOVETSKY, G (1987). Império do efêmero: a moda e seu destino nas sociedades modernas. São Paulo: Companhia de Bolso, 1987.

LUPTON, D. Personal data practices in the age of lively data. In: DANIELS, J.; GREGORY, K.; MCMILLAN COTTOM, T. (Org.). Digital Sociologies. Bristol: Policy Press, 2016.

MONTEIRO, R. O.; MAZZILLI, P. (2016). LIVE STORIES O Snapchat como uma pasta compartilhada de registros da vida. Intercom. Sociedade Brasileira de Estudos Interdisciplinares da Comunicação, Salto, p.1-15, jun.

PASTOR, L. (2016) Processo fotográfico: automatismo e retorno ao manual na prática da fotografia através do smartphone. Dissertação de Mestrado. Faculdade de Comunicação da UFBA, Salvador.

PERSICHETTI, S; KÜNSCH, D. (2013) A. Comunicação: entretenimento e imagem. São Paulo: Plêiade, 245 p. (Comunicação na contemporaneidade).

PIRES, G. T. S. (2013). FOTOGRAFIA ATRAVÉS DE DISPOSITIVOS MÓVEIS Estudo de caso sobre o Instagram. Revista da Graduação, Porto Alegre, v. 6, n. 1, p.176, maio.

REBOUÇAS, C. S; MENEZES, J. E. de O. (2016). Snapchat: o imediatismo imagético e os laços afetivos. Intercom - Sociedade Brasileira de Estudos Interdisciplinares da Comunicação, São Paulo, set.

RECUERO, R (2009). Redes Sociais na Internet. Porto Alegre: Ed. Sulina. 
SANTAELLA, L. (2008). Mídias locativas: a internet móvel de lugares e coisas. Revista Famecos, [s.1.], v. 15, n. 35, p.95-101, 13 set. EDIPUCRS. Disponível em: < http://dx.doi.org/10.15448/1980-3729.2008.35.4099>

SIBILIA, P (2008). O Show do Eu. Rio de Janeiro: Nova Fronteira, 2008

SILVA JUNIOR, J. A. (2014). Entre o Instagram e a Kodak. Expansões e ultrapassagens na cultura fotográfica contemporânea. Esferas, Brasília, v. 5, n. 3, jul., p.97-104. Semestral.

SILVA, W. C. L. (2010). O show do eu: a intimidade como espetáculo. Horizontes Antropológicos, Rio de Janeiro, v. 16, n. 33, p.277-280, jun. UNIFESP (SciELO). Disponível em: <http://dx.doi.org/10.1590/s0104-71832010000100015> 